\title{
Orthodoxy and Customs the Basic Sources of Sadism: A Psychoanalysis of the Caretaker
}

\author{
Muntazar Mehdi ${ }^{\mathrm{a} *}$, Muhammad Mumtaz Ali Khan ${ }^{\mathrm{b}}$, Shabana Rasool ${ }^{\mathrm{a}}$ \\ ${ }^{a}$ Faculty of Social Sciences, National University of Modern Languages, H-9 Islamabad, Pakistan. \\ ${ }^{b}$ National College of Business Administration \& Economics (NCBAE) Lahore, Pakistan.
}

Received: 16 July 2020 / Revised: 10 August 2020 / Accepted: 10 December 2020

\section{Abstract}

In contemporary world, humans in social context recurrently ascend against the deliberate and inadvertent occurrences as they fall debilitated intellectually and experience the antagonistic effects of social issues. The current research paper tries to bring up the purposes for sadism issue with exceptional reference to social part of people's life, thinking about society and specialists as main thrusts behind pretty much every dejection by means of putting on Freud's psychoanalytic assumption about mental issues (yet through a minute unorthodoxy) on an emotional character made from Pinter's imagination in "The Caretaker". This descriptive study highlights the core area of human life with respect to sadism and orthodoxy from the content of the play. The content has been undertaken to investigate, decipher and evaluate with reference to Freudian viewpoint in order to open up people's enormous job of making sadism issue within society through pushing them to choke themselves in specific manners. The study brings forth the feature that the communication gap and loneness is one of the major reasons of sadism and orthodoxy.
\end{abstract}

Keywords: Dejection, Isolated, Irrationality, Incapability, Sadism, Societal Association.

\section{Introduction}

Comprehension of "psychoanalysis", by the help of its twofold personality having supposition just by means of a treatment to fix psychological infections, has been a basic apparatus to collaborate with such kind of personality disorders and it is also convenient to investigate the figurative dramatization of Herold Pinter's universe as Thurshwell (1998) describes "Freud's theory, psychoanalysis suggested new ways of understanding amongst other things, love, hate, childhood, family relations and the conflicting emotions" (p.23). Creative and reformed presumptions of Thurshwell about oblivious piece of person's perception in actuality have been a strong reason for explanatory investigation of a person's psyche relatively of scholarly content. Thurshwell (1998) also sheds some light on how Freud interprets additional expected significance to unconscious by saying that "For Freud, everything is unconscious before it is conscious" (p.36). As an abstract idea of decoding human mind, psychoanalysis draws investigation to the covered up artistic writings full of unpredicted thoughts in conceived people. This also suggests an everincreasing number of potential outcomes to unfurl the concealed intentions behind the actions and activities performed by a

\footnotetext{
*Corresponding author: E-mail: mumtazali1214@yahoo.com (Muhammad Mumtaz Ali Khan)

Available online: 30 December 2020

DOI: https://doi.org/10.34154/2020-ASSJ-0202-24-32/euraass

Journal reference: Arts and Social Sciences, 2020, 1(1):24-30.

ISSN-E: 2743-4664

(c) European Academy of Applied and Social Sciences. Euraass - 2020. All rights reserved.
} 
character. Eagleton (2003) perceives "psychoanalysis" as "Secondary revision" towards uncovering approximately any "sub text" (p. 48). Nervousness of and depression remains a kind of powerlessness in adjusting one's condition, one's failure for changing one's life designs, and a failure for building up a fantastic character.

Russon (2003) characterizes unhappiness as "The way a tension - frustration of desire - is structured into our very approach to things" (p. 19). Additionally, he elaborates depression by saying "The neuroses mark the inability to coordinate the sectors of habitual life coherently" (p. 31). For this purpose of examining manifestations about sadness Fenichel (2005) argues that "All symptoms give the impression of something that seems to break in upon the personality from unknown source" (p. 18). Refining us with his ideas about psychoanalysis regarding the explanations for people's sadism issue, Boeree (2007) draws that "Predisposing psychological conditions... One's culture... triggering stressors in people's lives lead to the various emotional, behavioral and cognitive symptoms of neurosis" (p.128). Along these lines, society and culture through suppressions direct people behind differences of the norms in contemporary world to their own set of ethics which live in unconscious of the individuals. Eagleton (2003) brings up towards this very reality by saying that "These are the cultural, political and economic sphere of life... that lead a man towards disorder" (p. 67). Harold Pinter with in his sphere of characterization extends distressed, confused and irritating state of present-day people. "The Caretaker", presents Aston as most obvious psychotic, and also an unadulterated case for an individual harmed and ridiculed by the general public. His wrongdoing has uniquely been portrayed as undisturbed action the direction of the world for which he has been rebuffed throughout the play. Character analysis of Aston also suggests that the society doesn't treat its faults rather it tries to find them Aston.

A number of literary studies have been carried out on Herold Pinter's works with regard to different issues described by the writer in "The Caretaker" which indicate mental problems with respect to the characterization involved in the play. Moreover, it is vibrant through verifying the current literature that analysis has not investigated the chosen play so far as per explicit utilization of psychoanalytic view of orthodoxy and resulting sadism. Along these lines, it becomes crucial to decipher the character of "Aston" sketched up in the hands of Pinter with unique reference to sadism as the character has appropriately been made fortified for concentration below the referred term. The social order, authorities and the public encircling in them are the genuine conceding powers designed for a person and by means of these powers, there are the forces intended to crush the singularity and individual image of the people. In a meeting in which Herold Pinter was inquired as to what purpose his main characters remain in a single room and what was the reason for their fear? Pinter answered, "Obviously they are scared of that is outside the room. Outside the room there is a world bearing upon them which is frightening. I am sure it is frightening to you and me as well" (Esslin, 1989, p.43).

Gillen (1992) sensibly shows society's rough expectations for slaughtering singular image of individuals. He explains that "Whether they use brain - shock therapy or force, the goal is always the same: to destroy the individual's belief in himself and his own vision of life"(p.81) which being contradicted to inner self leads to serious personality disorders as sadism is one of them. Additionally, he uncovers the unbearable job of the social order and authorities by arguing that they will likely "make him (individual) doubt himself by placing impossible demands upon him and thus reduce him to an automaton" (p.83). The antagonistic character of Aston in "The Caretaker" is a depiction of deceived individual who has been compressed by the society while implementing mind activity on him. Burkman (2011) portrays him as "A victim of society, and of his own mother whose permission was needed for the operation. Aston failed to make his escape" (p.9). "The Caretaker" is an account of mistreatment of individual image and thought. Innes (2008) says, "The Caretaker is yet another study in victimization mental (Aston, with his psychiatric history), physical (Mick, leather-jacketed and unpredictably violent) and emotional (Davies, the elderly vagabond)" (p.235).

The world's domineering flora is similarly uncovered by Patil (2009) who says that "The so-called society does not allow him to be the part and parcel of society. Therefore, Aston is forced to lead isolated life and the character like him is given inferior treatment in society" (p.38).Aston as character much God gifted and talented remains less valuable individual in the contemporary society. Esslin (2011) comments "Aston is the poet whom society crushes under the weight of its machinery of legal forms and bureaucracy. His hallucinations, his clear visions having been wiped from his brain" (p.185). Assessment of the past writing could be inferred in the expressions made by Innes (2008) that "The socially accepted normality is discredited by his revelation that electric shock therapy has left him a mental cripple" (p.318). Moreover, he thinks about the effect of societal abuse happening on the psyche and the life expectancy of people and says "The shocking nature of the process that has reduced Aston to conformity implies that social conditioning is the equivalent of political oppression" (p.329).

The Orthodoxy and multi layers of customs in the society make people absurd, suppress the creativity and free thought and ultimately lead to sadism. People in any social context have many social and individual relationships which influence the current interactions of social actors. In order to keep the solacing life going on, the presence of some conducive social interactions need to 
be maintained for sustainable social life. The current study has been taken up to examine the levels of unhappiness and orthodoxy in society with reference to the 'The Caretaker' from the theatre of absurd. This research peeps through human issues related to mental problems caused by the societal pressure. It helps people understand the issue which bring about sadness in the social context. It will also highlight how people can avoid letting the sadness intervene in their lives. This paper finds out the societal dilemma of "Aston" in precise, motives of communication disaster in "The Caretaker" and the probable answers which may be brought into the light by the psychoanalysis. There are major questions about Aston such as (a) how does the societal pressure work on the thinking capacity of Aston?, (b) what types of situations are involved to in "The Caretaker" which led people to sadism? And (c) how common creativity is affected by orthodoxy and customs in "The Caretaker"?

\section{Research Methodology}

This is a qualitative study with the descriptive design of the play from the theatre of absurd. The qualitative approach has been proposed with respect to descriptive method in order to find out the communication failure, sadism, and societal pressures created by orthodoxy and customs described in "The Caretaker". Psychoanalysis is chosen to be applied in this research paper to find out societal dilemma of "The Caretaker". Psychoanalysis puts light on the different mental issues faced by the today's man.

\subsection{Theoretical Framework}

"psychoanalytic" review of Sigmund Freud has been proposed as it has been proved an explanatory and basic methodology for the investigation of problems and disorders of individual's thought mostly influenced by the contemporary society as Pinter's "The Caretaker" is a fine example to reveal society and the authority in the background of individual's anxiety while major focus has been given to. In the wake of covering Freudian archetypal of psychological issues on the designated content, the applicable parts are unveiled to fortify the opinion that singular anxiety is the result of the hypocritical and inflexible social orders. The investigation of the pertinent essences of the content uncovers a severe power that leads people towards variations from the norm like hypochondriac attitudes. Hypothetically, Freud's philosophy of limited unconscious, which as a result drives in the direction of chronic mental disorder and sadism issues, fills in as theoretical foundation of the current examination. Freud thinks about passive need for sexuality at the base of individual sadism and personality disorders and yet he also acknowledges the significance of devastating social and economic circles of life.

Perhaps, to accept aimlessly sexuality behind each mental issue will be an exceptional issue or misguided judgment as mentally the fundamental needs of people are to be taken care of and may be secured correctly. Anthropological relationships in truth are significantly dictated by their rational power which ever paternalistic or communal. Along these lines, nonsensical power can be found by way of the underlying driver of individual's dejection. Walter (1965) acknowledges the way that has been measured a commonsense part of lifecycle or a "reality principle" that mashes the distinction of the people. He offers an expression "Pleasure principle indeed under the influence of the external world is changed into the more mode reality principle" (p.213). Walter additionally clarifies that in what way social orders and public establishments develop issues in people even though he says "Under the influence of some cultural urges some civilizations...possibly the whole mankind has become neurotic" (p.216).

\section{Data Analysis}

According to Sigmund Freud, isolation which can be seen in present-day person from his associated individuals, surroundings and connections has a certain side effect of anxiety on a person's thought. Walter (1965) clarifies the said opinion while arguing that "In an individual neurosis we take as our starting point the contrast that distinguishes the patient from his environment, which is assumed to be normal" (p.154). To investigate the matter to the degree of Pinter's characterization in "The Caretaker" Aston can determined as a hypochondriac character that has been destroyed by the contemporary society for his aesthetic vision. "The Caretaker" can be considered a most engaging and most talked about play written by Pinter and also a case of Pragmatist Theater. Mick says in the beginning of the play, "Every word you speak is open to any number of interpretations" (Pinter, 1961, p.176). Pinter may have specified that announcement nearby his self-arguments while the implication that it has been seen that Pinter himself and his characterization clearly appear as indifferent to all social and policy driven issues although the drama yet from the inside and out investigation illuminates the entire social, financial and dogmatic situation. All the major characters in "The Caretaker" are by all means looking for their personalities so altogether at specific stages are confronting the issues related to 
sadism, anxiety and hopelessness. The dissatisfaction of the characters against the unbelievable social order and framework brings nearly broken and scattered characters. Burkman (2011) brings up in the direction of this very point by arguing that "In nearly compliments, the three typescripts in The Caretaker are all destitute, all in pursuit of their individuality identifications in a money-oriented biosphere" (p.186). Pinter wisely uncovers the dreadful job of societal order and the ruling classes form olding individuals as psychotic and the other discovery is their merciless treatment towards those dejected people. As per Stephen's (2017) argument "In Davies, Pinter shows his audience how society treats its rejects; in Aston, he shows them how it creates them" (p.129). Aston can be considered as the finest depiction from the Pinter's characterization in the play "The Caretaker" who may suitably be named as dejected character. At the point when the play proceeds, the act anticipated previously the audience Aston is in the room. The wreckage and mixed state of the apartment is represented to the scrambled and turbulent considerations of the individual residing in that chamber. Stephen (2017) depicts a similar thought while he argues that "The room also acts as an emblem for the state of Aston's mind. It is full of cobbler items and junk, a bizarre mixture of valuable and valueless items, unorganized and in disarray" (p.132).

Other than tangled considerations, Aston's presence in front of the audience has not been just a demonstrating his antagonistic conditions, however, his congruity too. The costume which is shown on Aston's body is one that is given to the patients in emergency clinics, and according to Pinter it is an indication of comparison. "Aston wears...a thin shabby dark-blue pinstripe suit" (Pinter, 1961, p. 15). Stephen (2017) depicts the scenario in his words that, "Aston...wears a shabby pinstriped suit that was given to him at the hospital. This form of clothing is often associated with conformity and respectability" (p. 151). By the use of that clinical dress, the authorities assist and endeavor to modify Aston's perspective from nonconformist to a conventionalist that has been considered appropriate for authorities and societal order. Throughout the play, it can be discovered that Aston is occupied with his screw drives, attachments, and electrics. He brings no useful output from all his instruments, does nothing advantageous truly with the electrical gadgets yet retains himself occupied constantly in such exercises. It represents Aston's disappointment in repairing the attachments as well as his inability to impart and retain connections with society.

Anyhow, to the sum of his endeavors, Gabbard (1981) sees these circumstances by arguing that, "The electric plug that Aston is forever probing is also symbolic of his experience" (p. 119). Moreover, Gabbard (1981) explains, "The shock treatment of the fiendish trick, real or imagined, is connected in his mind with electricity - pincers. Aston is forever trying to mend his plug, make it work again; undo the damage which was done" (p.121). Aston can't discuss appropriately with Davies. More often than not he talks excessively less and offers short responses and a few periods around are long addresses indicating Aston's internal twisted ailment. His discourse needs cognizance and familiarity. His reaction to Davies' inquiries is more often than not exactly unreasonable as shown in the following lines;

"DAVIES: How many Blacks you got around here then?

\section{ASTON: What?}

DAVIES: You got any more Blacks around here?

ASTON: (holding out the shoes). See if these are any good (Pinter, 1961, p. 12)."

This disappointment about correspondence has been by virtue of Aston's failure to connect the considerations organized appropriately. Aston all through the drama stays flighty and the peculiar one character. Aston is seen more often than not wanting to leave the chamber preoccupied by the outside air. This causes audience to sense that he senses himself troubled and needs to take improvement and relaxing over outside air and even in serious chilly weather condition, he can't rest without leaving the windows open of his apartment. All the components referenced about Aston's character makes him a vague entity till he conveys a lengthy discourse toward the end of the Act Two in which the argument has at last been exposed. Though, Aston's discourse reveals not just the job of society and the effect of that job on Aston's character, yet it additionally carries the pursuers and audience nearer to Aston and causes them to sense the desolation and torment which Aston is experiencing. The secret is settled at long last and the truth is very exposed be forehand in Aston's discourse. This discourse illuminates Aston's unusual character and conduct which speaks to him to be a masochist just as it is displaying the entire situation of the explanations for his hypochondriac issue. Aston explains, "I used to go there quite a bit. Oh, years ago now. But I stopped... I want to build that shed out in the garden" (Pinter, 1961, pp.52-55). Although in this discourse, we reach at a point to realize that in what way social order is liable of providing and creating issues in Aston's character. His contemplations throughout the discourse are dissipated and upset and uncover individual of his character plainly. This discourse uncovered the savagery of current social orders to people. This also reveals us how the supposed society demonstrations its reluctance for aesthetic people who are of minute or no financial interest 
for it at all. Aston's wrongdoing has only been that talks excessively which is less intelligible for some time.

Stephen (2017) carries Aston's personality front of the world by explaining that, "He (Aston) talked to people, and talked too much. He could have been a political revolutionary, an industrial activist, or simply a rebel, someone not prepared to accept immediately and without question what society asked him to believe" (p.127). At that point, moreover, Stephen uncovered the horrendous plans prepared by societal elements and its implementation of mind activity on him. He further says, "His operation can thus be seen as society's retribution, and a symbol of the fear in which it holds the person who is a potential threat to it" (Stephen, 2017, p. 144). Such hazards, in a cruel manner, immediately abolishes in sad situation by captivating away Aston's capability to reason. The genuine quandary uncovered by this discourse is that society is not prepared to let anybody talk as indicated by one's personal determination and requirements. This acculturated society is really an uncouth one in its disposition that it cannot endure individuals who belong to a group of fewer help for it. By means of this discourse, we reach at a point to think approximately of the uselessness of interdependence. Aston discloses that in what way his mother, alongside the evil authorities of the general public and emergency clinic, designed a treatment contrary to him for wrecking his emotional posture. Aston's scrutinizing the Mother Nature ends up being a danger for himself in light of the fact that the cruel societal order and its delegates won't give anybody the option to get any progressions the pre-established framework.

Patil (2009) thinks about this idea by highlighting that, "As it was dangerous to the society, his (Aston's) questioning ability was hampered by electric shock therapy...Then Aston not only loses questioning ability but also fails even to communicate properly" (p.141).Aston describes that in what way social order measured and affirmed him a distraught and afterwards he chooses to work just as to dispose of his talking tendency. He is oppressed and somewhat annihilated by the general public so as to make him an innocuous individual for society. Gillen (1992)uncovers savage goals in front of the social order activity by arguing that, "Equally Len in The Dwarfs and Aston from The Caretaker has been imperiled to electric mental rehabilitation handling until they are brought from their individual thinking of realism which the social order believes illusions" (p.194). He additionally goes with his scholarly opinion that after the electric shocks he used recall his pleasant past memories and his previous existence when was an ordinary individual with a less societal pressure. In any case, with the awful cerebrum activity his own vision was finished, and the explanation for this domineering treatment towards Aston was his propensity for going on and on. His unmistakable delusion was made obscure by the implications of the orthodoxy while working on his cognizance. Prentice (2005) explains that in what way "Aston, like Davies and Mick, cherishes illusions about himself. He believes he once had but has now lost clear vision and an ability to talk to other people easily" (p.189). Aston discloses that once in what way he has been ready to be thoughtful appropriately and settle on choices as per his personal determination and command. Aston's personal image has been the utmost valuable possession that he possessed yet his psychological capacity, reasoning and even his character were misplaced due to mal treatment of the contemporary society. Gabbard explains, "He once saw things very clearly, had hallucinations; these phrases suggest that Aston witnessed the primal scene". Moreover, he argues about how he has been demolished, muted and objectified by the authorities.

Gabbard (1981) articulates about this fact by arguing that, "When he tragically talked about it, they quieted him, they diverted him and lead him to a psychological upset that made him incapable to rational thinking and reluctant to converse" (p.117). As Aston's discourse passes to its denouement, steadily obscurity wins up until everything with the exception of Aston becomes dim and imperceptible. This is to call it the sincere prediction of Aston's lifespan after the cerebrum activity. Society harmed his societal face to a greater extent and carried his life to the dimness with the authorization of creation of agonizing mind procession Aston. He cannot reason yet his innovativeness that has been crushed by the orthodoxy and contemporary customs. At the moment the circumstance can be describe as that despite the fact that Aston is flourishing truly yet he is lifeless at the same time and completed intellectually from his inner self-conscious inside. As per Prentice (2005), "Aston was quieted, intellectually demolished, injured" (p.117).

Because of the motion in vogue, outrage has been communicated via Aston's contempt, disapproval and distance in the direction of society and the subsequent estrangement has been shown appeared via his conduct and treatment to Davies. In spite of the fact that he fetches the old beggar (Davies) into his chamber and provides him spot to stay there yet unfit to destroy the mass of bizarreness worked by the general public towards him and to different populations. Prentice (2005) argues, "It's hard for him yet he makes an endeavour to be cordial and it simply doesn't work" (p.121). At long last, Aston has been prepared for taking care of the general public by a similar character trait. He chooses to sing the old homeless person (Davies) away who has been symbolizing a representative of contemporary society. He safeguards Davis from a chilly night and gives him shelter under his 
chamber and also would expel him in an equivalent extreme cold. Finally, the later arise sat the point where Aston has been shown absolutely a more unusual and merciless to, Davies, the old homeless person as if Davis was never known to him. How the stupendous expectation may be made by the society from him, for example, he will ensure as revenge what was done to him by the same society. Likewise, this can be taken as an indication of mental issues as a part of Aston's character that how he treats Davis in dual way and is presently prepared for making his self-ideal world.

Prentice (2005) proposes that, "Having once been executed by society, he is reluctant to be killed once more" (p.126). At this point, Aston is being made detached and estranged and has been assigned a duty upon his awful mind to perform that same activity carried out by the individuals from the compromising society so as to acquire him harmony for people surrounds him. Detachment of Aston is the aftereffect of his excess of faith in strangers in the public eye. Aston's disconnection is not the shortcoming yet of the general public. After the inside and out examination of the content and character analysis of Pinter's representation of psychological issues by inventing the character of Aston, this is something which turns out to be evident that Aston is living some place at good ways from the limits of typical mental domain. He neglects to convey, neglects to create connections with his fellow beings just on a contemporary social closure. It has been additionally uncovered that whatsoever he is at present stage, he has been the result of a framework of customs and the orthodoxy general opinion. Thus, society on one or the other way is driving individuals in the direction of psychotic issues as described in Aston's character as well.

\section{Conclusion and Findings}

This study reveals the problems and disorders of individual's thought which is mostly influenced by the society. Isolation is one of the main causes of anxiety. If a person has no social interactions, that may suffer the anxiety issues. It is a psychological problem. "The caretaker" in which the characters are shown having a lack of communication gap. The most conversation between characters is based on the single room. They have fear of going outside. The isolation which can be seen in present days has a certain side effects of anxiety. As we have discussed how multi layers of customs in the society make people absurd, suppressed, lack of creativity and the free thought which leads to sadism. The writer uncovers the unbearable job of the social order and authorities with their false code of conduct mostly applied for the benefit of a social class to suppress the other. This also shows people who seem physically good and strong but they may be suppressed by the code applied by customs and orthodoxy which is quite unnatural and incompatible with human race especially when it refers to human psychology. Aston's struggle to survive in the poor conditions is exactly the portrayal of a modern man who wants to achieve something (like Aston in the Caretaker) but due to certain restriction on him he only can plan without implementations. Electrocution in the play exactly serves as the penalty comes on a person when he goes against the widespread manmade orthodoxy and customs.

In the wake of investigating and deciphering "The Caretaker" by presented by Pinter with reference to the philosophy given by Freud, the current explorative work reasons that anthropological distinction remains in interrogation by the arrows of the ultimate social orders. The psychological collapses and sicknesses in people may not be considered and comprehended by leaving aside the communal part of people's lifecycle. The cutting-edge social frameworks where we are living just like Aston's general public is by all accounts working with the target of making all of us conventionalists. It upholds conventionalism with such power that a singular feels himself/herself defenceless to go up against it because of its confinements. These constraints and vulnerability transform the person into an outsider and more peculiar who is spellbound by the forces outside his ability to control. The conditions of an individual if horrible they may be break and separate his character in the society. It has been described a tale of a person who holds doubts after the antagonistic biosphere wherever his independence is not sheltered enough. It is reasonable to say that, by contemporary social order and the way of governance imposed by the authorities, we are all left with nothing except our references and papers some place in the form of records and having lack of individual thought or identity. We generally sense we have "cards of personality" at some place much more difficult to reach than "Sidcup".

The reference of "Sidcup"is such a spot that is difficult to grasp. Minogue(1983)argues about "Sidcup" that "A place which seems to derive from the same myth-making impulse as the Garden of Eden, where we mislaid our innocence and our nobility but if the weather would break, we might dash back and get them" (p. 214). As there is a great concern between language and psychology so it is possibly the best approach of having some grasp of how The Caretaker proceeds is to focus on the association among language, context and psychology. In Pinter's drama criticalness is not generally revealed in the words a character possesses. It is thus inadequate to state, "What do these words mean?" Rather one should present requests like: "For what reason does this character say this starting at now" or "What is the character's method of reasoning in saying this?" or "What are the essential interests that regulate this talk or exchange?" This cuts off the conventional association between language and context. 
For example, there is a particularly split exchange among Davies and Aston in the scene in the second exhibit after Aston prescribes to Davies that he might be gatekeeper. Looking at the language in conventional semantic terms may incite the end that it speaks to simply bungling inarticulacy. Anyway in case one looks in past with the semantics of language in widespread phonetic terms in order to consider the subject of possible motivation and the exchange is not altogether clear: Davies would not care to yield to taking the movement of manager that Aston obviously offers him; he is playing for time; he can't appreciate why anyone should need to do him a not too bad turn; if he says yes he is focused on he may fall into the catch. In this play, in like manner, the language the characters use does not generally have any close relationship to what they may mean. Furthermore, in Pinter's performance, language use cannot be helpfully separated from the subject of power as essentially all associations are depicted as power clashes or something to that affect.

\section{References}

Boeree, C. G. (2007). A Bio- Social Theory of Neurosis. Retrieved from http://webspace.ship.edu/cgboer/genpsyneurosis.html [Accessed 11 October 2019].

Burkman, H. C. (2011). The Dramatic World of Harold Pinter: Its Basis in Ritual. Ohio : Ohio State University Press.

Eagleton, T. (2003). Literary Theory: An Introduction. South Minneapolis: The University of Minnesota Press.

Esslin, M. (2011). The Theatre of the Absurd. New York : Penguin.

Fenichel, O. (2005). The Psychoanalytic Theory of Neurosis. London: Routledge.

Walter, D. (1965). Civilization and its Discontents. (Strachey, J, Trans.). New York: W.W.Norton\& Co. (Original work published in 1929).

Gabbard, P. L. (1981). The Dream Structure of Pinter's Plays: A Psychoanalytic Approach. London: Associated University Presses.

Gillen, F. (1992). Nowhere to Go: Society and the Individual in Harold Pinter's The Hot house In Twentieth Century Literature. Vol. 29 No. 1. (pp-83-196). Hofstra University.

Innes, D. C. (2008). Modern British Drama: The Twentieth Century. Cambridge: Cambridge University Press.

Minogue, V. (1983). Taking Care of the Caretaker. In Ganz, A. (Ed.) Pinter: A Collection of Critical Essays. (p. 214). New Jersey: Prentice-Hall, Inc.

Patil, B. H. (2009). The Theme of Isolation in Harold Pinter's The Caretaker. Retrieved from http://www.thecriterion.com/v2/n3/patil.pdf [Accessed 23 September 2019].

Pinter, H. (1961). The Caretaker : A Play in Three Acts. London : S. French.

Prentice, P. (2005). The Pinter Ethic: The Erotic Aesthetic. New York: Garland Publishing Inc.

Russon, J. (2013). Human Experience: Philosophy, Neurosis, and the Elements of Everyday Life. New York : University of New York Press.

Stephen, M. (2017). Harold Pinter, The Caretaker: Notes. London: Longman.

Thurshwell, P. (1998). Sigmund Freud: Routledge Critical Thinkers: Essential Guides for Literary Essays. Massachusetts: Harvard University Press. 